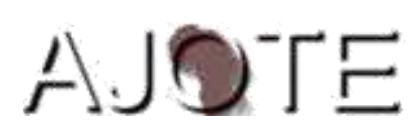

African Journal of Teacher Education

ISSN 1916-7822. A Journal of Spread Corporation

Volume $9 \quad 2020 \quad$ Pages $49-69$

\title{
Affordances and Constraints on Implementing Lesson Study for Teachers' Professional Development: A Review
}

\author{
Jimmy Ezekiel Kihwele ${ }^{1,2}$ \& Guoyuan Sang ${ }^{1}$ \\ 1. Faculty of Education, Beijing Normal University, P. R. China \\ 2. Department of Education Foundations and Teaching Management, \\ Mzumbe University, Tanzania.
}

\begin{abstract}
Lesson Study (LS) has been adopted worldwide as a research tool for teachers who teach the same subjects to cooperate in identifying problems, planning a lesson, teaching that lesson and coming up with solutions to the problem identified. This helps them grow professionally. This study is a review of approaches to implementing $L S$ in different places, of opportunities that the use of $L S$ provides, and of constraints on its effectiveness and sustainability. In this study, 30 published research articles were thoroughly studied and analyzed so as to answer three key questions that serve as its underpinning. The findings show that the methods used to implement LS vary in many places. However, in several cases, LS practitioners try to implement the original structure of LS as it was implemented in Japan in the 1960s. The findings show that LS affords more pedagogical opportunities than constraint: teachers learn new professional skills and knowledge and they improve their understanding of the subject matter, and change their attitudes, beliefs and views on collaborative working.
\end{abstract}

Keywords: Lesson study, teacher professional development, in-service teachers, teaching practices

\section{Introduction}

Lesson study (LS) has been widely adopted as a method of professional development for both preservice and in-service teachers. Several studies have reported challenges and obstacles relating to 
traditional Teacher Professional Development (TPD) models in improving and updating teachers' professional skills (Ono \& Ferreira, 2010; Tan, Chang, \& Teng, 2015). According to Ono and Ferreira (2010), traditional TPD models train teachers to follow rigid and prescribed expert-driven top-down patterns. Such models use cascading methods to train teachers to improve their pedagogical and content knowledge and the training times are usually short and occasional.

Kelly (2006), Kelani and Kourey-Bowers (2012), and Hennessy, Habler and Hofmann (2015) have explained as a drawback of the traditional TPD models, the wrong belief it instils in teachers that TPD can be achieved merely by attending occasional workshops, seminars or meetings. The use of the traditional models has seen governments expend scarce resources for TPD without achieving set goals as some teachers are always after incentives that come with it rather than learning (Ono \& Ferreira, 2010). These traditional TPD models have shown that 'one-time takeaway' training is less effective than school-based research models like LS. The former model has been associated with many teachers merely going after promotions, status and material gains rather than developing their professional competencies. The learning of such teachers thus does not result in them acquiring new skills and knowledge (Popova, Evans, Breeding, \& Arancibia, 2018). The cascading method of traditional TPD mostly reduce and dilute the intensity of what teachers learnt in training or seminars and, consequently, what they were going to share with colleagues who did not attend the training or seminars (Ezeugbor \& Chukwuemeka-Nworu, 2018; Hassler, Hennessy, \& Hofmann, 2018).

Kelly (2006) shows that teachers' expertise develops only gradually with the transformation occurring through collegial interaction and via teaching practices within the working environment during normal daily routine. Wells (2000 p. 4) observe that learning is "the transformation that continuously takes place in an individual's identity and ways of participating through his or her engagement in particular instances of social activities with others". Teachers need to change the belief that professional development depends on activities that detach them from their teaching environment, and largely on activities facilitated by people coming from the outside of teachers' working contexts. The LS can be a sustainable method of TPD to help teacher move towards expertise (Lewis, Perry, \& Murata, 2006). Its adoption and implementation though, requires initiatives for making skills and practices part of teachers' routine activities. Once teachers have 
internalised the values of LS, they will gradually transform their beliefs, attitudes and practices regarding teaching and learning process.

LS is the planning, teaching and examination of samples of lessons prepared and given by teachers for the purpose of learning and improving their practices collaboratively (Saito et al., 2006). LS originated in Japan, where it is called 'Jogyou-Kenkyu,' a method of improving lessons through collaborative working. The goal of LS is that teachers be able to produce high-quality lessons with a significant impact on learners (Thinwiangthong, Inprasitha, \& Loipha, 2012). The collaboration involves teachers who teach similar subjects sharing their experiences in terms of both content and pedagogy. The adoption of LS gives a signal of hope as it has proven to be a sustainable method of teacher learning through planned practices and collaboration with others (Coe, Carl, \& Frick, 2010; Lewis \& Perry, 2014; Thinwiangthong et al, 2012). Understanding various implementation approaches, how teachers have benefited from LS studies, and the challenges they faced and how they solved them are very important.

The US, a late adopter of LS, borrowed the initiative from Japan after learning its seemingly effective practices in transforming teachers' pedagogical and content knowledge. Various approaches were used [by who?? in the US?] in different contexts in implementing LS; these include integrating different theories, customizing the procedures to fit specific contexts, and focusing on either teachers' practices or students' performances.

Some African countries are in the early stages of adopting LS. South Africa and Zambia have systemically integrated it in their teacher education system. The World Association of Lesson Studies (WALS) website shows that its 2018 annual conference received 6 papers from two African countries, namely South Africa (3) and Zambia (3). Likewise, in 2019, there were 6 papers from five African countries, namely South Africa (2), Zambia (4), Ghana and Rwanda (1 each), and Tanzania (1). LS is thus gradually spreading to African countries. Hence, this is the right time to synthesise the affordances and constraints for proper planning and successful implementation of LS, the task that we set for ourselves in this paper.

This study reviews and synthesises studies to understand the approaches used to implement LS, how it offers opportunities for teachers to cooperate in planning lessons, in teaching and reflecting on those taught lessons, and in identifying weak points and how to improve the teaching activities to strengthen their professionalism. We also examine the constraints of implementing LS. This 
review contributes to the existing literature by informing the continuing spread, adaptation, and innovation pattern of LS across various contexts around the world. To achieve this goal, the review addresses the following questions.

i. What approaches are used to implement LS for teachers' professional development?

ii. What are the affordances of LS in teachers' professional development?

iii. What are the constraints on effective implementation of LS for teachers' professional development?

\section{Methodology}

The review employed a systematic qualitative review approach (Gikandi, Morrow \& Davis, 2011). This review began by searching for peer-reviewed articles which were published between 2006 and 2019, the period when LS reached Africa. Articles were downloaded from Springer, SAGE, Science Direct and JSTOR.. The searching concepts were 'lesson study TPD', 'lesson study implementation', 'using lesson study in-service teacher training', 'lesson study as a school-based teacher training' and 'teacher coaching through lesson study'. A total of 172 articles were obtained and sorted in keeping with the research objectives mentioned above. Articles that did not reflect the themes required to answer the review questions and those which did not have practical and empirical evidence of LS were excluded from the study. A total of 183 articles were obtained and sorted in keeping with the research objectives. Table 1 shows the geographical distribution of all articles obtained.

Table 1: Articles specific geographic locations

\begin{tabular}{lll}
\hline Location & Country & $\begin{array}{l}\text { Number of } \\
\text { articles }\end{array}$ \\
\hline Asia & Singapore & 14 \\
& Indonesia & 15 \\
& Japan & 32 \\
& Pakistan & 20 \\
Europe & Netherlands & 11 \\
& England & 14 \\
& Turkey & 10 \\
\hline
\end{tabular}




\begin{tabular}{lll} 
North & The US & 41 \\
America & Canada & 3 \\
Australia & Australia & 9 \\
Africa & South Africa & 7 \\
& Zambia & 4 \\
& Uganda & 1 \\
& Malawi & 2 \\
& Ethiopia & 1 \\
Total & & $\mathbf{1 8 3}$ \\
\hline
\end{tabular}

Out of the total population of 183, we selected 30 articles using Weed's Methodological Guidelines for Review Papers (1997). The guideline provides for article inclusion and exclusion based on such criteria as time period, type of publication (peer-reviewed, conference proceedings), language of publication, study design, topic and population studied. Articles that did not meet the criteria were excluded from the pool for study. Articles from Japan were also excluded to fulfil the goal of reviewing articles on late adopters of LS for the purpose of providing a lesson to African countries. Furthermore, the sorting of articles was validated by the feedback obtained from the external reviewers who are experts in the field of LS. Of the 30 selected articles, $12(40 \%)$ were from North America, 11 (36.7\%) from Africa, 3 (10\%) from Europe and 4 (13.3\%) from Asia. The distribution in subject area were; Mathematics (55.6\%), Science (19.4\%), Pedagogy (13.8\%), Linguistics, Social Sciences, Physical Education and Early Childhood Education each (2.8\%). As depicted in the table 2, 5 (16.7\%) articles were published in African journals while the rest were published in journals outside Africa and in various international conferences websites.

The 30 articles were thoroughly studied and analysed to provide answers to the key questions of the study. The analysis involved extracting findings that reflected to key concepts of questions. The extracted information regarding affordances and constraints has been organised and presented in the sections below. The presentation and discussion have been organized to logically reflect the questions and they contain data from Africa, Europe, the USA and Asia. The published articles reviewed are presented in Table 1. 
Table 2: Summary of articles

\begin{tabular}{|c|c|c|c|}
\hline Author & Country & Subject & Category of data \\
\hline $\begin{array}{l}\text { Akiba and Wilkinson } \\
\text { (2016) }\end{array}$ & USA & STEM & $\begin{array}{l}\text { Deepening content knowledge, Limited } \\
\text { institutional support }\end{array}$ \\
\hline Baba \& Nakai (2011) & Zambia & Pedagogy & $\begin{array}{l}\text { Improve professional practices, Limited } \\
\text { research skills }\end{array}$ \\
\hline $\begin{array}{l}\text { Banda, Mudenda, Tindi \& } \\
\text { Nakai (2014) }\end{array}$ & Zambia & Sciences & $\begin{array}{l}\text { Improve professional practices, Time } \\
\text { requirement }\end{array}$ \\
\hline Bocala (2015) & USA & Mathematics & Boosting self-efficacy, Variation in learning \\
\hline $\begin{array}{l}\text { Chassels and Melville } \\
(2009)\end{array}$ & Canada & $\begin{array}{l}\text { Mathematics } \\
\& \text { Science }\end{array}$ & $\begin{array}{l}\text { Deepening content knowledge, experimenting } \\
\text { innovations, Boosting self-efficacy }\end{array}$ \\
\hline $\begin{array}{l}\text { Coe, Carl and Frick } \\
\text { (2010) }\end{array}$ & $\begin{array}{l}\text { South } \\
\text { Africa }\end{array}$ & Mathematics & $\begin{array}{l}\text { Improve professional practices, } \\
\text { Accommodating varying perspectives, } \\
\text { Variation in learning }\end{array}$ \\
\hline $\begin{array}{l}\text { Fauskanger, Jakobsen \& } \\
\text { Kazima (2018) }\end{array}$ & Malawi & Mathematics & $\begin{array}{l}\text { Variation in learning, Deepening content } \\
\text { knowledge }\end{array}$ \\
\hline $\begin{array}{l}\text { Fernandez \& Zilliox } \\
\text { (2011) }\end{array}$ & USA & Mathematics & Integrating theories \\
\hline Fujii (2013) & $\begin{array}{l}\text { Uganda \& } \\
\text { Malawi }\end{array}$ & Mathematics & Misconceptions \\
\hline Gero (2014) & USA & Mathematics & $\begin{array}{l}\text { Deepening content knowledge, Boosting self- } \\
\text { efficacy }\end{array}$ \\
\hline Hart and Carriere (2011) & USA & Mathematics & $\begin{array}{l}\text { Fostering collaboration, accommodating } \\
\text { varying perspectives, Change roles }\end{array}$ \\
\hline Inprasitha (2015) & Thailand & Mathematics & Experimenting innovations \\
\hline $\begin{array}{l}\text { Ishida, Mwanza, } \\
\text { Luchembe, Masaiti, \& } \\
\text { Nsama }(2016) * *\end{array}$ & Zambia & $\begin{array}{l}\text { Mathematics } \\
\text { \& Science }\end{array}$ & Limited institutional support \\
\hline $\begin{array}{l}\text { Leavy and Hourigan } \\
\text { (2016) }\end{array}$ & Ireland & Mathematics & $\begin{array}{l}\text { Fostering collaboration, Limited research } \\
\text { skills }\end{array}$ \\
\hline Lee and Madden (2019) & USA & Linguistics & $\begin{array}{l}\text { Improve professional practices, Boosting self- } \\
\text { efficacy, Change roles }\end{array}$ \\
\hline $\begin{array}{l}\text { Letloenyane \& Jita (2015) } \\
* *\end{array}$ & $\begin{array}{l}\text { South } \\
\text { Africa }\end{array}$ & Mathematics & $\begin{array}{l}\text { Improve professional practices, Limited } \\
\text { research skills }\end{array}$ \\
\hline Lewis and Perry (2014) & USA & Mathematics & Experimenting innovations, Limited research \\
\hline
\end{tabular}




\begin{tabular}{|c|c|c|c|}
\hline & & & skills \\
\hline $\begin{array}{l}\text { Meyer and Wilkerson } \\
(2011)\end{array}$ & USA & Mathematics & Time requirement, \\
\hline Mhakure (2019) & $\begin{array}{l}\text { South } \\
\text { Africa }\end{array}$ & Mathematics & Improve professional practices, \\
\hline $\begin{array}{l}\text { Norwich, Dudley, \& } \\
\text { Ylonen (2014) }\end{array}$ & $\begin{array}{l}\text { United } \\
\text { Kingdom }\end{array}$ & $\begin{array}{l}\text { Pedagogy } \\
\text { (learning } \\
\text { difficulties) }\end{array}$ & $\begin{array}{l}\text { Improve professional practices, Diagnosis of } \\
\text { students needs }\end{array}$ \\
\hline $\begin{array}{l}\text { Ogegbo, Gaigher \& } \\
\text { Salagaram (2019) ** }\end{array}$ & $\begin{array}{l}\text { South } \\
\text { Africa }\end{array}$ & $\begin{array}{l}\text { Physical } \\
\text { Education }\end{array}$ & $\begin{array}{l}\text { Improve professional practices, Varying } \\
\text { perspectives, boosting confidence, Lack of } \\
\text { time }\end{array}$ \\
\hline $\begin{array}{l}\text { Olson, White and Sparrow } \\
\text { (2011) }\end{array}$ & USA & Mathematics & Accommodating varying perspectives \\
\hline $\begin{array}{l}\text { Ono and Ferreira } \\
(2010) * *\end{array}$ & $\begin{array}{l}\text { South } \\
\text { Africa }\end{array}$ & $\begin{array}{l}\text { Mathematics } \\
\text { \& Science }\end{array}$ & $\begin{array}{l}\text { Improve professional practices, } \\
\text { Misconceptions, Limited institutional support }\end{array}$ \\
\hline $\begin{array}{l}\text { Rappleye \& Komatsu } \\
\text { (2017) }\end{array}$ & USA & Pedagogy & Misconceptions \\
\hline Saito and Sato (2012) & Singapore & $\begin{array}{l}\text { Science \& } \\
\text { Social } \\
\text { sciences }\end{array}$ & $\begin{array}{l}\text { Seclusion behaviour, Time requirement, } \\
\text { Stages of LS }\end{array}$ \\
\hline Saito et al., (2006) & Indonesia & $\begin{array}{l}\text { Mathematics } \\
\text { \& Science }\end{array}$ & $\begin{array}{l}\text { Fostering collaboration, Stages of LS, } \\
\text { Integrating theories }\end{array}$ \\
\hline Schipper et al., (2017) & $\begin{array}{l}\text { Netherland } \\
\mathrm{s}\end{array}$ & $\begin{array}{l}\text { Interdisciplina } \\
\text { ry }\end{array}$ & $\begin{array}{l}\text { Improve professional practices, Time } \\
\text { requirement }\end{array}$ \\
\hline Shingphachanh (2018) & Laos & Mathematics & $\begin{array}{l}\text { Limited institutional support, Stages of LS, } \\
\text { Integrating theories }\end{array}$ \\
\hline Sims and Walsh (2009) & USA & $\begin{array}{l}\text { Early } \\
\text { Childhood } \\
\text { Education }\end{array}$ & $\begin{array}{l}\text { Fostering collaboration, Improve professional } \\
\text { practices }\end{array}$ \\
\hline $\begin{array}{l}\text { Yadeta \& Assefa (2017) } \\
* *\end{array}$ & Ethiopia & $\begin{array}{l}\text { Pedagogy \& } \\
\text { Curriculum }\end{array}$ & $\begin{array}{l}\text { Fostering collaboration, Deepening content } \\
\text { knowledge, Seclusion behavior }\end{array}$ \\
\hline
\end{tabular}

** Articles published in African Journals

\section{Findings}

This section presents the findings obtained from the review of the articles and it is divided into three parts. First, the approaches used in various countries in implementing LS, second, the affordances of LS and the constraints of LS to TPD. 


\section{Approaches to Implementing LS}

The original LS model had features which were unique to it that were bound to the Japanese cultural context. According to Thinwiangthong et al. (2012), the original LS had three steps, tagged, plan-do-see. Because LS is rapidly spreading into diverse cultural contexts, it continues to develop features which are different from those of the original version. The first variation is the that different scholars have designed LS with different stages. Ono and Ferreira (2010) and Saito et al. (2006) give three steps in implementing LS: planning, teaching and reflection. They are referred to as plan-do-see. Shingphachanh (2018) has added a fourth step; defining a problem. Coe et al. (2010) added two more steps, namely debriefing and result sharing. And yet other scholars have identified eight steps, i.e. defining a problem, planning a lesson in teamwork, teaching the lesson, reflecting and discussing that lesson, revising the lesson, re-teaching the lesson, discussing the retaught lesson, and sharing the results (Fujii, 2013). These steps vary depending on the extent to which practitioners want the implementation of LS to reflect specific contexts.

Lesson Study implementations have also included the integration of different theories as part of the approaches suited to diverse contexts. For instance, social learning theories have been used to link TPD with the context and culture of the workplace. Fernandez and Zilliox's (2011) practices are based on research on socio-cultural learning theory developed by Vygotsky. Bocala (2015) used the socio-cultural theory which explains that novice teachers gradually become experts through interacting with experienced mentors in their working contexts. Kelly (2006) used Wenger's social theory of learning that assumes socio-cultural contexts to be responsible for TPD. The authors made assumptions that "knowledge about teaching is socially constructed through learning communities." Ono and Ferreira (2010) integrated the constructivist theory which argues that the gradual process of rethinking what is taught, how it is taught, and how learning is assessed collaboratively in a specific context help teachers to construct new and better content and pedagogical knowledge. Ono and Ferreira (2010) further show that teacher learning is constructed from interaction and collaboration within their socio-cultural contexts. Gero (2014) also supports the position of the socio-cultural learning theory in TPD that "teaching is not simply a set of procedures, but a cultural activity." 


\section{Affordances of LS on TPD}

Lesson Study has many success stories around the world with respect to its contribution to TPD. The following sub-section gives a summary of the evidence obtained from the studies reviewed. Many African countries which are yet to adopt LS TPD can consider these affordances.

\section{Fostering collaboration and self-reflection}

One character of high-quality teachers is their ability to collaborate and work in teams so as to achieve a common goal. LS has helped to develop collaboration among teachers teaching similar subjects (Saito et al., 2006; Sims \& Walsh, 2009; Coe et al., 2010). Collaboration means planning and designing lessons together, observing what others are teaching, criticising their wrong practices and critiquing their approaches and commenting on their best practices (Fujii, 2013; Leavy \& Hourigan, 2016; Lee \& Madden, 2019). The collaboration will help get rid of the tendency of working individually, self-confining to narrow understanding and acting rigidly, not allowing others to see what one does in the classroom and what their teaching plan is (Hart \& Carriere, 2011). The LS thus helps teachers to open up their mind to learn from colleagues through collaborating in lesson activities.

\section{Deepening knowledge of the subject matter}

In some contexts, teachers do not have the opportunity to attend formal out-of-school TPD programmes to update their knowledge of content and pedagogical skills (Gero, 2014; Laddunuri, 2012; Magidanga, 2017). Studies show that teachers can benefit in terms of improving their content and pedagogical knowledge by implementing LS (Chassels \& Melville, 2009; Meyer \& Wilkerson, 2011; Akiba \& Wilkinson, 2016). Participants can acquire a good mastery of the subject matter that will influence pedagogical practices like leading students' discussions and changing the way of asking questions from reciting texts from readings to more application of knowledge in real-life situations (Olson, White, \& Sparroe, 2011).

Improving professional practices in schools

High standard professional practices are those which merge professional theories and actual classroom practices. Student teachers learn theoretical aspects of teaching at college and they expect to merge them with routine practices at schools through the mentoring process (Coe et al., 2010). As Meyer and Wilkerson (2011) argue, teachers adopting the LS can learn new and appropriate instructional methods. In the same line of thought, Leavy and Hourigan (2016), Lewis 
and Perry, (2014), Sims and Walsh, (2009) point out that this deepens their understanding of the proper methods of managing students' behaviour. More adaptive teaching competencies will be developed which are important for professional growth (Schipper, Goei, de Vries, \& van Veen, 2017).

Furthermore, LS helps teachers to link their classroom teaching practices with broader educational objectives and goals (Ono \& Ferreira, 2010). This linkage makes teachers more flexible and dynamic in using a variety of instructional methods to actively engage students in learning activities in the classroom. Teachers develop capabilities to accommodate different views, perspectives, and ideas about teaching and learning (Saito et al., 2006). The new insights developed helped teachers to be more creative and they transform their practices (Lee \& Madden, 2019). LS offers teachers a continuous learning opportunity so that they can identify challenges and find solutions to them by transferring knowledge to new contexts (Coe et al., 2010; Fujii, 2013).

\section{Experimenting with innovations}

In the process of implementing LS, new, creative, innovative ideas emerge and are tried in an experimental way that may impact teachers' professional practices (Chassels \& Melville, 2009; Inprasitha, 2015; Lewis \& Perry, 2014; Schipper et al., 2017). Moreover, LS can activate inquiry that helps teachers to dive into vast resources and come up with new methods, solutions and practices that may improve their teaching and influence students' competencies (Chassels \& Melville, 2009).

\section{Accommodating varying perspectives in teaching and learning}

Teachers hold certain perspectives, beliefs and views concerning teaching methods and styles as well as the ways of developing their professional skills (Olson et al, 2011). Some teachers believe in the objectivity of individual practices, as Coe, Carl and Frick (2010) report. In such cases, teachers dominate over teaching with limited students' involvement because they regard students as passive, without ability, and with the need to be filled with knowledge and skills (Inprasitha, 2015).

In LS, through collaboration, teachers are encouraged to open up their mind to learn and share their practices with their colleagues for self-development purposes (Lee \& Madden, 2019). The collaboration from LS helps teachers to develop the culture of self-criticism, openness and acceptance of different perspectives (Hart \& Carriere, 2011). Criticism and challenges are useful resources for TPD. Accepting different perspectives leads to teachers' change of practices like 
improving abilities in asking diagnostic questions, understanding students' needs and interests as well as activating students' participation in classroom discussions (Olson et al, 2011).

\section{Boosting teachers' self-efficacy}

Teachers' confidence is central to facilitating the learning process (Chassels \& Melville, 2009). This confidence should come from mastering the subject matter, from appropriate selection of pedagogical methods to facilitate learning, and from the ability to manage students' behaviour (Lee \& Madden, 2019). Using LS, teachers develop confidence through detailed explanations that provides solutions to the problems they have been facing (Hart \& Carriere, 2011). Teachers who have been involved in planning, teaching, observing and in reflecting on lessons in a series of LS have transformed their pedagogical practices in managing lesson delivery in the classroom and thus, gained more confidence than those who have not participated in them (Gero, 2014; Hart \& Carriere, 2011). Novice teachers benefit much from LS cycles (Bocala, 2015; Shingphachanh, 2018). Collaborating with experienced colleagues allows novice teachers to get a better understanding of actual classroom situations which is different from how they perceived it during teacher education training, thus enhancing their confidence (Akiba \& Wilkinson, 2016).

\section{Changing role of teachers}

Lesson studies have influenced teachers to change not only their perspectives and beliefs towards the teaching profession, but also their role in class. According to Lee and Madden (2019), teachers and principals have changed their roles, from being evaluators to being coaches. Teachers support learners in constructing and applying knowledge in real-life situations, and not in accumulating knowledge. The shift from teacher-centred teaching methods to learner-centred teaching methods helps students to learn and teachers to develop their pedagogical skills so that they can improve their delivery of lessons (Hart \& Carriere, 2011). Lesson studies enable teachers to be aware of what students understand and how to correct their constructed knowledge.

\section{Constraints in implementing LS}

The interpretation and implementation of LS, in different contexts, face several constraints. These constraints result from misinterpretation of LS cycles and the right starting point, cultural challenges, little experience in implementing LS and variation of interest participating teachers. These constraints are explained in the sections below.

Misconception of LS by practitioners 
LS has been contextualised so that it fits into different geographical and cultural settings which are important in modifying the structure of LS for its successful implementation (Meyer \& Wilkerson, 2011). The more LS is localised, the more it deviates from its original version (Lee \& Madden, 2019). Originally, LS focused on collaborative teacher-learning activities for the purpose of improving classroom instruction and content knowledge (Akiba \& Wilkinson, 2016; Rappleye \& Komatsu, 2017). Currently, in the USA, LS is used not only to improve classroom instruction, but also to improve leadership skills (Lee \& Madden, 2019).

In the US, as well as African countries, where LS has been implemented, teachers misinterpret LS by focusing a strict implementation of its steps to accomplish the planned content rather than teaching it as a lesson so that learners understand the concepts (Chassels \& Melville, 2009; Ono \& Ferreira, 2010). In Malawi and Uganda, some teachers find it difficult to adhere to their agreed upon customized steps of LS while others apply LS as a 'fixed script' and focus on the given stages within a prescribed time rather than ensuring a normal flow of the lesson based on learners needs and interests (Gero, 2014; Fujii, 2013; Meyer \& Wilkerson, 2011). Thus, participating teachers strive to complete the planned LS steps rather than focuse on pedagogical aspects of the lesson. Also, some participating teachers were known to have decided to adapt and customise the LS cycles so that they can fit into their specific contexts. All this results in confusion. (Hart \& Carriere, 2011). They end up unable to produce lessons like the original Japanese ones (Rappleye \& Komatsu, 2017).

Referencing Indonesia, Saito et al. (2006) show that teachers did not know whether they should consider students' feedback as important in improving classroom instruction or only consider the lesson planned and how teacher delivered it to the class. The same findings were reported in the US context (Bocala, 2015). Some researchers argue that observing students' facial expressions, comments in discussions, murmurings and rates of participation in classroom learning process(i.e. students' feedback) can provide more information to teachers about the quality of their instructions in a particular lesson they have planned and taught than could students grades from assessment (Saito et al., 2006). This observation, they argue, will help teachers to develop pedagogical skills and get better understanding students' behaviours.

In Africa, the US, Europe and Asia, the studies done in science and mathematics subjects outnumber those which have been done in other fields (Bocala, 2015; Fujii, 2013; Hart \& Carriere, 
2011; Meyer \& Wilkerson, 2011; Olson et al., 2011; Ono \& Ferreira, 2010). Since many LS studies are in mathematics and science subjects, teachers have developed a belief that LS is for science subjects only (Sims \& Walsh, 2009). According to Rappleye and Komatsu (2017), if the misconceptions are not cleared, there is a danger of failing to harness the potentials of LS in impacting teachers' knowledge of the subject matter and pedagogical skills in all disciplines of learning.

\section{$L S$ requires ample time to implement}

Time is an important resource in facilitating and accomplishing the implementation of LS (Coe et al., 2010; Meyer \& Wilkerson, 2011). Teachers have to implement LS cycles which in some cases goes to a second or more phases until a fine version of the lesson has been developed (Leavy \& Hourigan, 2016; Schipper et al., 2017). In many contexts, it has been difficult for teachers to go to the second or third phase of LS cycles due to limitation of time (Hart \& Carriere, 2011).

For instance, in Japan, some cases of LS spanned from six months up to one year to complete full LS cycles (Fujii, 2013). In this context, Akiba \& Wilkinson (2016) claim that teachers meet every week to work on LS activities. In other countries where they have localized LS to fit their contexts, it also consumes a considerable amount of time. Saito and Sato (2012) have argued that occasional rather than sustained meeting for TPD put the effective implementation of LS is in doubt. Spending short time to implement LS limits the analysis of the planned and implemented lessons, hence hinders teachers in reforming lessons (Gero, 2014).

\section{Seclusion behaviour of the teacher affects $L S$}

The basic requirements of LS include teachers' willingness to collaborate and work in teams to achieve a common goal. In the USA, South Africa and Japan, some teachers have a culture of working in isolation and they do not want to be observed when they are preparing lessons or are engaged in classroom teaching (Chassels \& Melville, 2009; Coe et al., 2010; Hart \& Carriere, 2011; Saito \& Sato, 2012). As pointed out by Olson et al. (2011) and Ishida et al. (2012) such isolation tendency develops when teachers cannot stand criticism from colleagues and when they feel insecure and are less confident. Furthermore, many teachers believe that teaching is an individual practice, hence they perceive LS as an activity that adds more responsibilities to their task (Hart \& Carriere, 2011; Gero, 2014). Inprasitha, (2015) has observed that isolation culture among teachers affects the formation of LS groups, making it difficult for LS to succeed (Saito et al., 2006). Such 
isolation behaviour affects the prosperity of LS as it limits collaboration and learning from reflection on teachers' teaching practices (Olson et al, 2011).

In some cases, teachers who passively joined LS groups did not concentrate on observing lessons, some walked out during the lessons (Hart \& Carriere, 2011; Rappleye \& Komatsu, 2017; Saito et al., 2006). Chassels \& Melville (2009) indicate that some teachers held beliefs and practices of individualism and never changed those beliefs even after participating in a series of LS cycles. The consequences of the seclusion behaviours is a fragmented learning achievement, as some teachers develop new knowledge that improved teaching practices and others did not learn any new knowledge (Schipper et al., 2017).

\section{Limited research skills among teachers}

Lesson study is action research by nature, requiring accomplishment of the research procedures that will lead to TPD (Akiba \& Wilkinson, 2016; Bocala, 2015; Lewis \& Perry, 2014; Shingphachanh, 2018). The process of gathering data through observing lessons that are being taught and sharing the findings requires strong research skills (Hart \& Carriere, 2011; Schipper et al., 2017). So also does the presentation of the findings. The possession of limited research skills by some teachers, unfortunately, hinders effective implementation of LS (Coe et al., 2010).

To fill the research skill gap among teachers who participate in LS activities, schools should collaborate with universities' experienced researchers to build research skills in teachers to help them improve the implementation of LS cycles (Leavy \& Hourigan, 2016; Shingphachanh, 2018). Experienced researchers from universities should act as coaches to guide teachers to adopt LS for TPD (Hart \& Carriere, 2011). Saito et al. (2006) and Inprasitha (2015) both stress that schooluniversity collaboration is vital for the effective implementation of LS. Once some success has been made, the experts could slowly withdraw to give full autonomy to school teachers while they employ occasional follow-ups to monitor progress. The withdrawal process will empower teachers and make them independent researchers in schools.

\section{Variation of the amount of learning and level of experience}

While Lesson Study encourages collaborative learning approach, the amount of learning acquired depends on individual teachers' self-efforts, attention and devotion during the implementation of LS. Bocala (2015) noticed that combining novice teachers and experienced teachers in LS process could lead to an unpredicted problem of the former focusing on the lesson content and the latter on 
students' responses. In evaluating the effectiveness of the LS on TPD the two sides (novice and experienced teachers) will have different views. Ono and Ferreira (2010) also highlights that practice variation was noted among teachers who participated in LS. Hence, as noted by Bocala, participating in the LS does not guarantee improvement to teaching practices of all teachers equally unless the teachers are committed to learn and improve and unless their experience variations are taken into consideration in the LS process. The variation of learning, therefore, is limited to individual interest to improve pedagogical and content knowledge and the level of experience among the collaborating teachers (Coe et al., 2010).

\section{Limited institutional support}

In some contexts, institutional management does not provide the LS with the required support despite LS being the learning activity that starts from the grassroots to improve teachers' pedagogical competencies (Schipper et al., 2017). Principals assign teachers extra duties and changes in the school timetable and the changes made in curriculum affect LS activities (Ono \& Ferreira, 2010; Shingphachanh, 2018). Teachers' average working time per week in the US are 26 hours while in Japan they are 17 hours (Akiba \& Wilkinson, 2016), this may explain the success of LS in Japan and the USA since teachers have enough time to participate in LS. In Zambia, some principals had a negative attitude towards LS as they perceived it adds more to the responsibilities at school (Ishida et al., 2012). Chassels and Melville (2009) as well as Saito and Sato (2012) show that teachers have varying workload and the school schedule may limit teachers' participation in LS.

The success of LS depends on the perfect collaboration between principals, teachers and students in creating workable environments (Inprasitha, 2015). It has been difficult in some places for principals to attend LS meetings due to the burden of their administrative responsibilities or because they have little interest in the initiative. But it has been observed that teachers take LS activities seriously when principals participate in LS cycles. The presence of principals motivates teachers to effectively participate in the learning process..[provide a reference for this] In more advanced stages, LS require additional financial resources and electronic facilities for recording and displaying the sample lessons taught in the class and when they find they cannot provide the required resources and facilities, some principals lose interest (Hart \& Carriere, 2011). 


\section{Discussion}

The findings show that approaches used in implementing LS vary in different contexts. Emulating the original LS procedures as were implemented in Japan is difficult due to variation in sociocultural and environmental contexts. Any attempt to copy the original LS version will hinder the effective implementation of LS in localized contexts. In adopting LS, it is recommended to customize it to fit in the targeted contexts, considering cultural, political, economical and social aspects (Meyer \& Wilkerson, 2011). Teachers should be free to design LS to fit in their working environments and get all the necessary support. There are variations in teachers' workloads and school timetable hence localizing the LS is important as it offers a chance for teachers and schools to initiate LS activities. Studies by Shingphachanh (2018) and Ishida et al. (2012) show how teachers' heavy workload affects the implementation of LS. Therefore, principals should consider LS as part of school activities. The working context in developing countries calls for practitioners to be more innovative in localizing the LS for successful implementation.

Lesson Studies have improved teachers' perception, attitudes and views of teaching practices. Teaching roles have changed in all contexts; teachers have acquired innovative pedagogies that put learners at the centre of learning process and has broadened content knowledge among teachers. Individualistic cultures of teachers working in isolation have changed to a large extent in the US and Asian cases except in cases reported from the African context, although effective implementation of LS in Africa will eliminate the isolation culture among teachers. Schools should work to adapt LS to foster not only to collaboration among teachers to influence students learning but elevate teachers' pedagogical and content knowledge. Although teachers still need the training to shape their experience in broader aspects, the LS allows them to collaborate, build teachers' confidence and inquiry mind, to innovate and try new ideas, which will add value to the discussions on matters pertaining training and seminars that teachers attend.

The LS practitioners should consider the varying experience between members in LS groups: experienced members taking the responsibilities of coaching the novice towards TPD. Experienced members should, however, refrain from dominating the discussion so that all teachers could learn from each other. In Asian and US cases, the implementation of LS has created more mentors whereas in African countries, many LS projects are at initial stages of adoption. Unfortunately, a considerable number of these teachers are abandoning the initiative, considering 
LS to be impossible to implement in their contexts ( Ono \& Ferreira, 2010; Yadeta \& Assefa, 2017). There is, therefore, a need to plan for methods of sustaining LS practices in the long run.

Teacher education institutions should intensify research courses to promote LS practices to teachers. In the few African cases discussed here, external researchers have been responsible for initiating and implementing LS while schoolteachers have been involved as participants with limited autonomy. In some schools, teachers lacked adequate research skills and were dependant to researchers. This situation calls for collaboration between schoolteachers and research experts from universities to empower schoolteachers in implementing LS activities.

The theoretical perspectives learned from the experience of LS practices in places that have reported success can help in improving the implementation of LS in diverse directions. Although theories act only as the blueprint, still they guide practitioners to get rid of misconceptions and have the perfect cycles of LS. From socio-cultural learning perspectives, school culture and social contexts of the working environment have great impacts on LS. The perspectives about LS impact on TPD can be categorized into six elements of a transformative framework: context, collaboration, procedures, reflection, teacher-learning, and teacher identity.

Mobilizing LS groups should be preceded by obtaining teachers' consent to participate in the learning process. LS organizers should diagnose teachers' needs and interest of what they want to learn and improve. Rules and regulations to guide the process, for instance, stipulating the responsibility of group members, the appropriate language to use in commenting, critiquing and giving suggestions for improving LS should be framed in advance. The presence of rules and regulations may prevent members from dropping out during the LS process and encourage them to fully participate in LS activities. LS should not be associated with monetary benefits since participants may be conditioned by money and not the need for TPD. Involvement of financial benefits may jeopardize the prosperity and sustainability of LS activities.

\section{Conclusion and recommendations}

Teachers have transformed their beliefs, attitudes, teaching roles in the classroom as well as knowledge of subject matter. Teachers should be empowered with research skills and schools should include LS in their timetables while teacher education institutions should integrate LS courses in their teacher preparation programs. The collaboration between schools and universities should be embraced to create a viable environment for LS to succeed. Total dependence on external 
researcher limits teachers' autonomy and jeopardizes the future of LS because teachers may believe that implementing LS depends on external researchers. Perfection of LS cannot be achieved in a short time given the many intervening factors involved; it is achieved only as a gradual process involving a cycle of LS activities. Teachers should be intrinsically motivated to participate in LS for TPD, as it will help them to own the responsibility of learning to improve their teaching practices. More studies should be done and directed to understanding institutional culture and its impact on teachers' adoption of LS.

\section{References}

Akiba, M., \& Wilkinson, B. (2016). Adopting an International Innovation for Teacher Professional Development: State and District Approaches to Lesson Study in Florida. Journal of Teacher Education, 67(1), 74-93. https://doi.org/10.1177/0022487115593603

Bocala, C. (2015). From Experience to Expertise: The Development of Teachers' Learning in Lesson Study. Journal of Teacher Education, 66(4), 349-362.

Chassels, C., \& Melville, W. (2009). Collaborative, reflective, and iterative japanese lesson study in an initial teacher education program: Benefits and challenges. Canadian Journal of Education, 32(4), 734-763.

Coe, K., Carl, A., \& Frick, L. (2010). Lesson study in continuing professional teacher development: A South African case study. Acta Academica, 42(4), 206-230.

Ezeugbor, C. O., \& Chukwuemeka-nworu, I. J. (2018). Models and Delivery Methods of In-service Teacher's Professional Development Programmes of Federal Government Colleges. International Advanced Journal of Teaching \& Learning, 4(1), 1-13.

Fujii, T. (2013). Implementing Japanese Lesson Study in Foreign Countries : Misconceptions Revealed. Mathematics Teacher Education and Development, 16(1), 119-135.

Gero, G. (2014). The prospects of lesson study in the US. International Journal for Lesson and Learning Studies, 4(1), 7-25. https://doi.org/10.1108/ijlls-02-2014-0007

Hart, L. C., \& Carriere, J. (2011). Developing the Habits of Mind for a Successful Lesson Study Community. In L. C. Hart, A. Alston, \& A. Murata (Eds.), Lesson Study Research and Practice in Mathematics Education: Learning Together (pp. 27-38). New York: Springer. 
Affordances and Constraints on Implementing Lesson Study for Teachers' Professional Development: A Review

Hassler, B., Hennessy, S., \& Hofmann, R. (2018). Sustaining and Scaling Pedagogic Innovation in Sub-Saharan Africa: Grounded Insights For Teacher Professional Development. Journal of Learning for Development - JLAD, 5(1), 58-78.

Inprasitha, M. (2015). Transforming Education Through Lesson Study: Thailand's Decade-Long Journey. In S. J. Cho (Ed.), Selected Regular Lectures from the 12th International Congress on Mathematical Education (pp. 343-354). New York: Spinger.

Ishida, Y., Mwanza, P., Luchembe, M., Masaiti, G., \& Nsama, P. (2012). Scaling up Lesson Study in Urban and Rural Schools to Realize Sustainable, Inclusive Teacher Professional Development in Zambia. 247-269.

Kelly, P. (2006). What is teacher learning? A socio-cultural perspective. Oxford Review of Education, 32(4), 505-519.

Laddunuri, M. M. (2012). Status of School Education in Present Tanzania and Emerging Issues. International Journal of Educational Research and Technology, 3(1), 15-20.

Leavy, A. M., \& Hourigan, M. (2016). Using lesson study to support knowledge development in initial teacher education: Insights from early number classrooms. Teaching and Teacher Education, 57, 161-175. https://doi.org/10.1016/j.tate.2016.04.002

Lee, V., \& Madden, M. (2019). “We're in This Together": Principals and Teachers as Partners and Learners in Lesson Study. NASSP Bulletin, 103(1), 51-64. https://doi.org/10.1177/0192636519826717

Lewis, C., \& Perry, R. (2014). Lesson study with mathematical resources: A sustainable model for locally-led teacher professional learning. Mathematics Teacher Education \& Development, 16, 99-116.

Lewis, C., Perry, R., \& Murata, A. (2006). How Should Research Contribute to Instructional Improvement? The Case of Lesson Study. Educational Researcher, 35(3), 3-14.

Magidanga, F. S. (2017). Impediments Towards Enhancing the Pedagogical Content Knowledge to Secondary School Teachers In Tanzania. International Journal of Education and Research, 5(1), 273-284.

Meyer, R. D., \& Wilkerson, T. L. (2011). Lesson Study: The Impact on Teachers' Knowledge for 
Teaching Mathematics. In L. C. Hart, A. S. Alston, \& A. Murata (Eds.), Lesson Study Research and Practice in Mathematics Education: Learning Together (pp. 15-26). New York: Springer.

Olson, J. C., White, P., \& Sparroe, L. (2011). Lesson Study Research and Practice in Mathematics Education. In L. C. Hart, A. Alston, \& A. Murata (Eds.), Lesson Study Research and Practice in Mathematics Education: Learning Together (pp. 39-58). New York: Springer.

Ono, Y., \& Ferreira, J. (2010). A case study of continuing teacher professional development through lesson study in South Africa. South African Journal of Education, 30, 1-11.

Popova, A., Evans, D. K., Breeding, M. E., \& Arancibia, V. (2018). Teacher Professional Development around the World The Gap between Evidence and Practice (No. 8572). Washington, DC.

Rappleye, J., \& Komatsu, H. (2017). How to make Lesson Study work in America and worldwide: A Japanese perspective on the onto-cultural basis of (teacher) education. Research in Comparative and International Education, 12(4), 398-430. https://doi.org/10.1177/1745499917740656

Saito, E., Harun, I., Kuboki, I., \& Tachibana, H. (2006). Indonesian lesson study in practice: Case study of indonesian mathematics and science teacher education project. Journal of In-Service Education, 32(2), 171-184. https://doi.org/10.1080/13674580600650872

Saito, E., \& Sato, M. (2012). Lesson study as an instrument for school reform: A case of Japanese practices. Management in Education, 26(4), 181-186. https://doi.org/10.1177/0892020612445101

Schipper, T., Goei, S. L., de Vries, S., \& van Veen, K. (2017). Professional growth in adaptive teaching competence as a result of Lesson Study. Teaching and Teacher Education, 68, 289303. https://doi.org/10.1016/j.tate.2017.09.015

Shingphachanh, S. (2018). Teachers' understanding and concerns about the practices of lesson study in suburb schools in Laos. International Journal for Lesson and Learning Studies, 7(2), 150-162. https://doi.org/10.1108/IJLLS-12-2017-0062

Sims, L., \& Walsh, D. (2009). Lesson Study with preservice teachers: Lessons from lessons. 
Affordances and Constraints on Implementing Lesson Study for Teachers' Professional Development: A Review

Teaching and Teacher Education, 25(5), 724-733. https://doi.org/10.1016/j.tate.2008.10.005

Tan, A.-L., Chang, C.-H., \& Teng, P. (2015). Tensions and Dilemmas in Teacher Professional

Development. Procedia - Social and Behavioral Sciences, 174(February), 1583-1591. https://doi.org/10.1016/j.sbspro.2015.01.808

Thinwiangthong, S., Inprasitha, M., \& Loipha, S. (2012). Adaptation of Lesson Study and Open Approach for Sustainable Development of Students' Mathematical Learning Process. Psychology, 03(10), 906-911. https://doi.org/10.4236/psych.2012.310136

Well, G. (2000). Dialogic Inquiry in Education: Building on the Legacy of Vygotsky. In D. D. Lee \& P. Smagorinsky (Eds.), Vygotskian Perspectives on Literacy Research (pp. 51-85). New York: Cambridge University Press. 